\title{
Conserved Mechanisms, Novel Anatomies: The Developmental Basis of Fin Evolution and the Origin of Limbs
}

\author{
Amanda N. Cass ${ }^{1}{ }^{\mathbb{D}}$, Ashley Elias ${ }^{2}{ }^{\mathbb{D}}$, Madeline L. Fudala ${ }^{1}$, Benjamin D. Knick ${ }^{1}$ and Marcus C. Davis ${ }^{1, *}$ \\ 1 Department of Biology, James Madison University, 951 Carrier Drive, Harrisonburg, VA 22807, USA; \\ cassan@jmu.edu (A.N.C.); fudalaml@dukes.jmu.edu (M.L.F.); knickbd@dukes.jmu.edu (B.D.K.) \\ 2 Department of Biology, Missouri Western State University, 4525 Downs Drive, Saint Joseph, MO 64507, USA; \\ aelias1@missouriwestern.edu \\ * Correspondence: davis4mc@jmu.edu
}

Citation: Cass, A.N.; Elias, A.;

Fudala, M.L.; Knick, B.D.; Davis, M.C. Conserved Mechanisms, Novel Anatomies: The Developmental Basis of Fin Evolution and the Origin of Limbs. Diversity 2021, 13, 384 https://doi.org/10.3390/d13080384

Academic Editors: Raul E. Diaz and Eric Buffetaut

Received: 30 June 2021

Accepted: 11 August 2021

Published: 17 August 2021

Publisher's Note: MDPI stays neutral with regard to jurisdictional claims in published maps and institutional affiliations.

Copyright: (C) 2021 by the authors Licensee MDPI, Basel, Switzerland. This article is an open access article distributed under the terms and conditions of the Creative Commons Attribution (CC BY) license (https:// creativecommons.org/licenses/by/ $4.0 /)$.

\begin{abstract}
The transformation of paired fins into tetrapod limbs is one of the most intensively scrutinized events in animal evolution. Early anatomical and embryological datasets identified distinctive morphological regions within the appendage and posed hypotheses about how the loss, gain, and transformation of these regions could explain the observed patterns of both extant and fossil appendage diversity. These hypotheses have been put to the test by our growing understanding of patterning mechanisms that regulate formation of the appendage axes, comparisons of gene expression data from an array of phylogenetically informative taxa, and increasingly sophisticated and elegant experiments leveraging the latest molecular approaches. Together, these data demonstrate the remarkable conservation of developmental mechanisms, even across phylogenetically and morphologically disparate taxa, as well as raising new questions about the way we view homology, evolutionary novelty, and the often non-linear connection between morphology and gene expression. In this review, we present historical hypotheses regarding paired fin evolution and limb origins, summarize key aspects of central appendage patterning mechanisms in model and non-model species, address how modern comparative developmental data interface with our understanding of appendage anatomy, and highlight new approaches that promise to provide new insight into these well-traveled questions.
\end{abstract}

Keywords: limb development; paired fins; deep homology; fin-to-limb transition; Hox genes; evodevo; autopod; evolutionary novelty; sonic hedgehog

\section{Introduction}

From the fins of fishes to the wings of birds to human arms, paired appendage diversity has profoundly shaped the ecology and evolution of vertebrate animals. For this reason, appendage anatomy and evolution have been the focus of intensive study for centuries [1-4]. Anatomical and paleontological studies have illustrated the range of possible appendage phenotypes, the distribution of appendage characteristics across vertebrate diversity, and the patterns of appendage diversification writ large. Phylogenetics and systematics have suggested the order of origin of character states and provided directionality for transformational hypotheses of homology. However, neither anatomy nor phylogeny alone can elucidate the mechanisms underlying appendage origin or transformation, and these datasets also struggle to support homology of individual skeletal elements across anatomically disparate taxa. Early embryological studies went in search of both homology and mechanism. These studies, combined with modern molecular and developmental datasets, have made great strides in demonstrating the processes underlying appendage development and diversification and inform how we view the concept of homology. However, some longstanding questions remain, and answers have generated new lines of inquiry. In this review, we focus on comparative developmental studies that inform our understanding 
of paired-fin diversification and the fin-to-limb transition, and what these insights may tell us about the evolution of novelty.

\section{Anatomical Context}

Ancestrally, jawed vertebrates (gnathostomes) possess two sets of paired appendages: anterior pectoral fins and posterior pelvic fins. Pectoral and pelvic fins are homologous to the forelimbs and hindlimbs of tetrapods, respectively. However, historical patterns of loss, gain, and transformation of elements within these appendages make homologizing individual bones and morphological regions difficult when directly comparing members of highly derived lineages. A broadly comparative approach that integrates data from living species that retain ancient appendage characteristics and intermediate forms from the fossil record allows us to make informed comparisons of morphologically disparate taxa retaining few (or no) overlapping ancestral structures. Additionally, phylogenetic bracketing of critical nodes can be used to develop hypotheses regarding ancestral appendage states for major vertebrate lineages.

Fossil and comparative data suggest that the paired appendages of crown group gnathostomes (the clade that includes all living jawed vertebrates) were likely tribasal, with three bones (basal/proximal radials) articulating with the supporting girdle $[3,5,6]$. This arrangement was present in some extinct gnathostome lineages (e.g., placoderms and acanthodians) and is present in most of the members of the most basal extant gnathostome clade (Chondrichthyes), as well as some basal actinopterygians (e.g., Polypterus) [6,7]. Although a monobasal fin is a defining characteristic of all extant sarcopterygians, some extinct stem sarcopterygians possessed a polybasal fin articulation [8], further supporting the hypothesis that a tribasal fin is the ancestral condition for crown group gnathostomes.

In the late 19th century, Carl Gegenbaur [9] proposed that the archetypal gnathostome paired fin was organized into three morphological regions along the anterior-posterior (A-P) axis, each of which ancestrally contained a single basal radial. From anterior to posterior, these are the propterygium, mesopterygium, and metapterygium (Figure 1A). The anterior two regions exhibit a simple arrangement: a single anterior-most propterygium is followed posteriorly by one or more mesopterygial elements. However, the posterior metapterygium is distinctive in exhibiting a more complex arrangement where a single proximal-most element articulates with additional elongate elements distally, often in a "branched" pattern [5,7] (Figure 1A). All three regions are capped distally with an arch of nodular distal radials [7]. The absence of similar complex arrangements in the anterior radials suggests that the ability to produce multiple long branched elements is likely metapterygium specific, and that this region may possess some degree of developmental autonomy from the rest of the fin $[3,10]$.
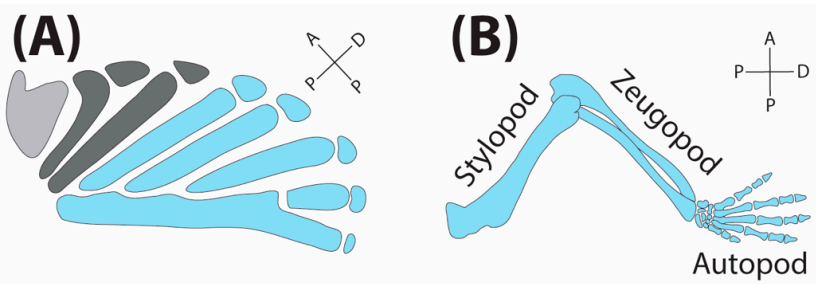

Figure 1. Representative fin and limb endoskeletal anatomy. (A) Pectoral fin endoskeleton of a non-teleost actinopterygian, the paddlefish Polyodon spathula, with fin rays removed for clarity. (B) Forelimb endoskeleton of a tetrapod, the mouse Mus musculus, highlighting proximo-distal regionalization of the appendage. Propterygium (light gray), mesopterygium (dark gray), and metapterygium (blue). Illustrations not to scale.

The majority of extant vertebrate diversity lies within the actinopterygian Teleostei and the sarcopterygian Tetrapoda, and both clades are characterized by the loss of one or more of the three ancestral A-P morphological regions (Figure 2). The paired fins of teleost fishes are polybasal [7]. Although Gegenbaur initially proposed that the fourth proximal 
radial of teleosts was a reduced metapterygial basal radial [5] (a hypothesis which has been repeated in modern times [3] and recently supported by compelling experimental data [10]), the more traditional interpretation is that teleost polybasal articulations are composed of only pro- and mesopterygial elements, and that the metapterygium has been lost, along with the ability to generate multiple long bones [11,12]. In contrast, tetrapod limbs possess a single element articulating with the supporting girdle (humerus of the forelimb; femur of the hindlimb). This arrangement of multiple long bones arranged along a single proximo-distal (P-D) axis has long been interpreted as retention of the metapterygium and loss of the propterygium and mesopterygium. In tetrapods, the metapterygium has become distinctly regionalized, along the P-D axis into the stylopod, the zeugopod, and the autopod (Figure 1B). Within these regions, the limbs of extant tetrapods follow a highly conserved osteological formula: in the stylopod, a single endochondrally ossifying element articulates with a supporting girdle (humerus or femur); in the zeugopod, two endochondrally ossifying elements (radius/ulna or tibia/fibula); and most distally, the autopod contains an array of many bones including the digits [13].

One of the defining differences between limbs and fins concerns the distal-most skeletal elements. Ancestrally, vertebrate appendages terminated distally in numerous fin rays. In contrast with the rest of the appendage skeleton, fin rays undergo dermal ossification (if they ossify at all). For this reason, they are termed the "dermatoskeleton", while the endochondrally ossifying elements make up the "endoskeleton" of the appendage. Fin rays are present in the fossil record and retained in extant finned vertebrates. In tetrapods, fin rays are absent, and the limb terminates instead with unbranched and endochondrally ossifying digits [13]. While more proximal ossified elements can sometimes be homologized between limbs and fins [14,15], there are no structural homologs of fin rays in tetrapods [16], and identification of digit/autopod homologs in finned vertebrates remains equivocal [17]. This pattern indicates that, in addition to the loss of the propterygium and mesopterygium, the evolution of limbs involved the loss of fin rays (Figure 2). Because in living species, dermal ossification in the fin only occurs distally and does not overlap significantly with regions producing endochondral bone, and because all traces of fin rays are lost simultaneously in the first limbs, the fin regions associated with endoskeletal and dermatoskeletal development are often considered as distinct morphological regions or modules [18-20] (but see References [21-24]). The loss of fin rays coincided with the elaboration of the endoskeleton to the distal margin of the appendage to form the autopod, which indicates that the evolution of the tetrapod limb also involved the gain of the autopod and potentially novel autopodial patterning mechanisms $[20,25]$.

Middle-to-Late-Devonian fossil assemblages reveal a diversity of sarcopterygians that inform our understanding of the patterns of loss and gain preceding the origin of tetrapods. The rhizodontid Sauripterus and the elpistostegalians Tiktaalik and Elpistostege possess extensive paired fin endoskeletons with proximal elements unambiguously homologous to the stylopod and zeugopod, and more distal elements that demonstrate a more variable pattern between taxa $[14,15,26]$. Sauripterus possesses a broad "fan" of distal endoskeletal radials, many of which are bifurcate [14] (Figure 2). In Tiktaalik, the distal fin skeleton consists of a complex arrangement of rod-like and blocky elements [15], and a recently described complete pectoral fin of Elpistostege demonstrates an extensive field of distal elements, including some that have been compared directly to digits [26]. In all of these taxa, the distal skeleton most likely represents the anatomical and developmental precursor of the autopod. Some groups of distal elements in these taxa demonstrate distinctive anatomical hallmarks of digits, such as articulating in proximodistal series, without significant differences in element shape, and without a branching pattern. However, other elements still show patterns of branching -intriguingly more so in Sauripterus than in Tiktaalik or Elpistostege. Although digits are a defining feature of extant tetrapods, a preponderance of anatomical and developmental data suggest that the origin of a distinct mesopodium (wrist/ankle) help mark the fin-to-limb transition [27,28]. Sauripterus, Tiktaalik, and Elpistostege all possess elements that can be homologized to mesopodial elements in the tetrapod wrist. These data 
support the notion that functional changes in how these appendages were used-such as for load-bearing in semi-aquatic or near shore environments $[17,20]$ - may have predated the loss of the dermal skeleton in the earliest tetrapods (i.e., Acanthostega [29]). However, the anatomy of intermediate forms bearing both an elaborate distal endoskeleton and fin rays raise questions about the relationship between dermatoskeleton reduction and endoskeletal expansion, and the autonomy of their underlying patterning mechanisms. In particular, the endoskeletal and dermatoskeletal elements in Sauripterus physically overlap within the fin [14], indicating a lack (or breakdown) of the spatial and mechanistic separation between the proximal and distal morphological regionality seen in other taxa $[20,21]$.

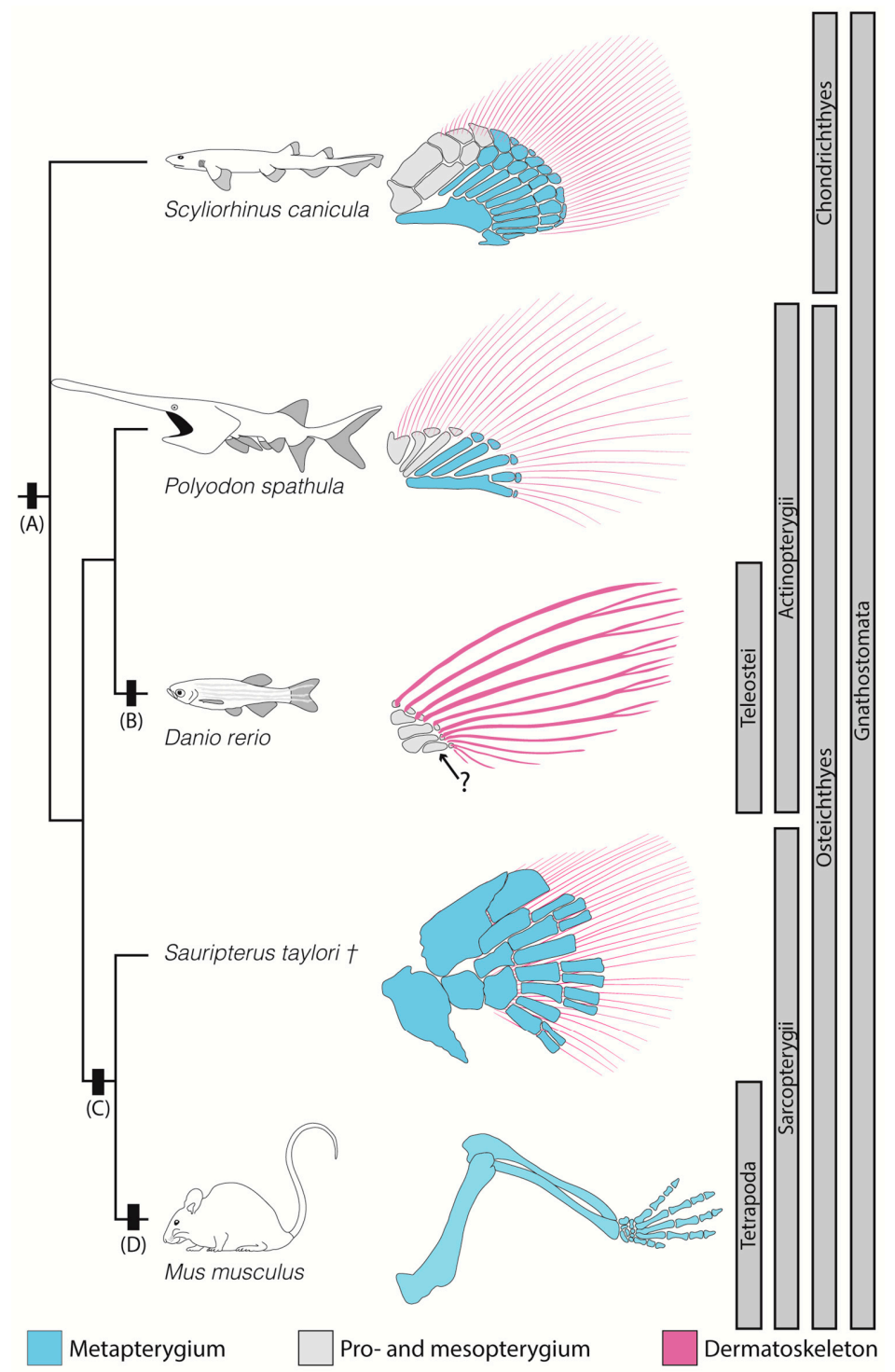

Figure 2. Patterns of anatomical loss and gain define paired appendage evolution. (A) Paired appendages are ancestral for gnathostomes, consisting of the pro- and mesopterygium (gray), metapterygium (blue), and fin rays (pink). This arrangement is conserved in catshark (Scyliorhinus canicula) and paddlefish (Polyodon spathula). (B) Teleosts (e.g., Danio rerio) possess a reduced endoskeleton composed of pro- and mesopterygial elements. In teleosts, the metapterygium has been either completely lost or is greatly reduced (see area indicated by the "?"). (C) Sarcopterygians are characterized by the loss of the pro- and mesopterygium and expansion of the metapterygium. (D) Within tetrapods, the limb is proximo-distally regionalized, with a distinctive distal autopod and the loss of the fin rays. Only pectoral appendages are shown here for clarity. Illustrations not to scale. 
Extant and fossil appendage anatomy provide snapshots of the fin-to-limb transformation. Patterns of loss and gain of elements suggest that appendages are composed of distinct morphological regions that behave semi-autonomously over the course of evolution, and that this pattern of organization has allowed for the range of observed appendage phenotypes. Understanding how these transformations occurred requires unraveling the developmental basis of appendage development in a comparative context.

\section{Tetrapod Limb Development}

\subsection{Integration of Limb Development}

The gene regulatory networks (GRNs) that integrate limb bud outgrowth and patterning have been partially characterized in mouse and chick, revealing many of the molecular mechanisms underlying anatomical and embryological patterns. Due both to the clinical significance of limb studies to human health and the availability of highly tractable tetrapod model systems, limb development is a reasonably well-understood process (reviewed by References $[30,31])$. This process begins with the formation of the limb bud. The location of the limb bud along the anterior-posterior (A-P) and dorso-ventral (D-V) axes of the embryonic flank is specified by expression of transcription factors in the Hox and Tbx gene families [32,33]. Once bud initiation occurs and the bud begins to elongate, additional signaling centers are established that regulate the D-V, A-P, and P-D axes of the developing limb itself.

\subsection{Limb Development: The AER and Fof-Shh Signaling}

A thickened layer of ectoderm along the distal margin of the limb bud, the apical ectodermal ridge (AER), regulates outgrowth and P-D axis polarity of the limb (reviewed by Reference [34]). The AER is molecularly distinct, expressing a cadre of the fibroblast growth factors (Fgfs), including Fgf4, Fgf8, Fgf9, and Fgf17 [35] (Figure 3A). Individual and combinatorial Fgf gene inactivation experiments demonstrate that not all Fgfs are equally critical for limb development; of single knockouts, only inactivation of Fgf8 produces a distinct limb phenotype [36]. Simultaneous conditional knockout experiments of $F g f 4$ and $F g f 8$ demonstrate that in $F g f 4 / F g f 8$ null mice limbs fail to develop, indicating that these two factors are particularly critical for limb outgrowth [37]. Limb-specific expression of $F g f 8$ is regulated by a complex genomic landscape of cis-regulatory elements (CREs); non-coding DNA sequences required for expression of a particular gene at a specific place and time. To date, seven distinct CREs have been identified that drive expression of $F g f 8$ in the AER [38-40].

The A-P axis of the limb bud is polarized by the posteriorly located zone of polarizing activity (ZPA), which expresses the secreted signaling molecule sonic hedgehog (Shh) [41] (Figure 3A). Expression of Shh in the ZPA generates a concentration gradient across the A-P axis of the bud and is associated with autopod development, where it provides positional information important for determination of digit number and identity $([41,42]$ and reviewed by Reference [43]). Although Shh is critical for development of a variety of embryonic structures, ZPA specific Shh expression is completely controlled by a single long-range CRE termed the ZPA Regulatory Sequence (ZRS). Deletion of the ZRS in mice results in a loss of limb Shh expression and a truncated limb phenotype [44].

There is considerable "cross-talk" between the AER and ZPA during the course of development, which provides the necessary coordination to develop normal limb morphology across both space and time (reviewed by Reference [45]). Diffusible signals from the AER and ZPA establish a positive feedback loop via intermediate signaling molecules and transcription factors expressed primarily within the limb bud mesenchyme (including Gremlin1, BMPs, and LIM-homeodomain transcription factors) (Figure 3A), and together these signaling molecules cooperatively pattern the developing limb [31,46]. Additional signals from the non-AER limb bud ectoderm are also involved in patterning the D-V limb axis [47]. A large literature exists detailing perturbation experiments that illustrate the phenotypic and gene-expression outcomes of morphological and molecular manipulation 
of the developing limb bud (reviewed by References [48,49]). These studies have demonstrated the network relationships between gene products and the causal relationships between altered gene expression and phenotypic variation.
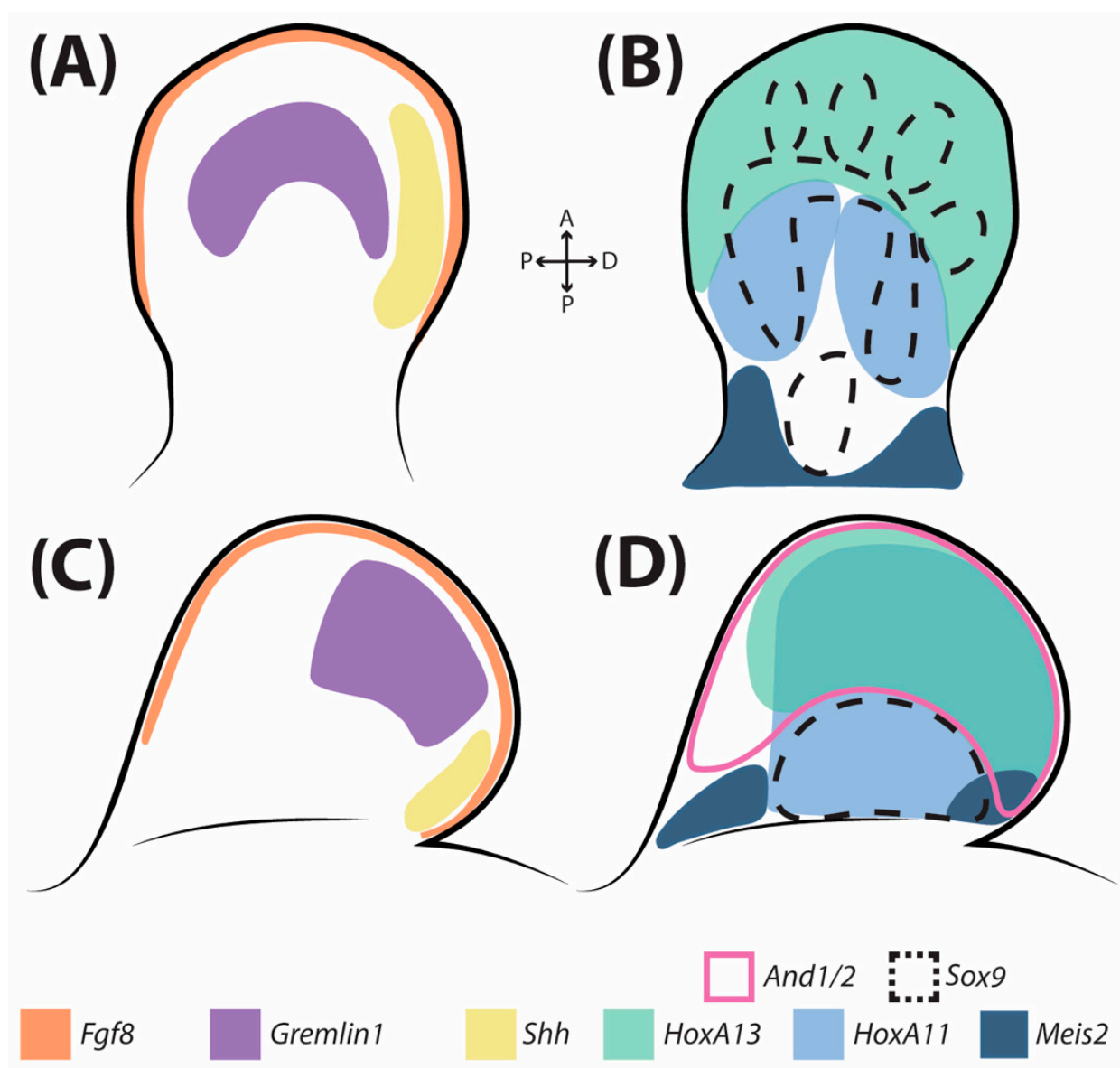

Figure 3. Fins and limbs are patterned by a conserved gene regulatory network (GRN). Representative limb ((A,B) mouse, Mus musculus) and fin ((C,D) paddlefish, Polyodon spathula) pectoral appendages. $(A, C)$ Expression patterns demonstrate conserved aspects of the Shh-Fgf feedback loop, including Shh in the zone of polarizing activity (ZPA), Fgf8 expression in the apical ectodermal ridge (AER), and Gremlin1 in the appendage mesenchyme. (B,D) Expression patterns demonstrate conserved aspects of proximo-distal patterning via HoxA network components. Markers for the presumptive stylopod (Meis2), zeugopod (HoxA11), and autopod (HoxA13) are also present in fins, but without the distinct regionalization present in limbs. Expression of Sox 9 and And1/2 marks the presumptive endoskeleton and dermatoskeleton regions, respectively. Illustrations not to scale; expression patterns adapted from References [21,22].

\subsection{Limb Development: Hox Regulation of Pattern}

The P-D axis of the limb is patterned by the combinatorial action of $5^{\prime}$ HoxA and HoxD cluster genes of the Hox family of transcription factors [50]. During early limb development HoxA and HoxD genes are expressed co-linearly, with more $3^{\prime}$ genes expressed earlier and more broadly, and $5^{\prime}$ genes expressed in a progressively more distally restricted pattern. In limbs, Hox genes are expressed in two phases: early and late. During the early phase, the more $3^{\prime}$ genes are expressed uniformly in the emerging limb bud, and more $5^{\prime}$ genes (HoxD10-13) are expressed in a progressively more restricted pattern along the P-D axis [49]. This nested pattern of expression is associated with the formation of the three limb regions. For example, in mice HoxA11 and HoxD11 expression is required for normal development of the zeugopod, and HoxA11/HoxD11 null mice display a foreshortened zeugopod phenotype [50]. HoxA13 and HoxD13 are required for normal autopod development, and 
double mutant mice completely lack digits [51]. Additional Hox-associated genes are also involved in P-D regionalization of the limb, such as the $5^{\prime}$ Hox co-factor Meis. In RNA in situ hybridizations, Meis1/2 expression marks the region of the developing stylopod [52] (Figure 3B). However, Meis1/2 conditional knockouts and overexpression mutants generate both stylopod and zeugopod phenotypes, suggesting that Meis genes also play a role in the development of the zeugopod [52-54]. Further characterization of Meis1/2 expression in mice suggests that Meis is in fact expressed in a gradient, with high levels proximally and a distal Meis-free zone, and that this gradient regulates distal HoxA expression [54].

The second phase of expression is modulated by Shh from the ZPA, and the most $5^{\prime}$ HoxD genes pattern the autopod with inverse co-linear expression (HoxD13 is more broadly expressed, HoxD10 is most restricted) [55]. Late-phase Hox expression is associated with autopodial development, and in its absence, mouse embryos fail to develop an autopod [49].

The regulatory landscape surrounding the tetrapod HoxD cluster and its relationship to early and late phase limb expression has been extensively characterized [56-58]. The HoxD cluster is surrounded by a "regulatory archipelago" of CREs associated with regulation of HoxD expression [58]. These elements are located both $3^{\prime}$ and $5^{\prime}$ to the Hox cluster, and early phase and late-phase expression, as well as expression collinearity, are regulated by distinct enhancer regions [57-59] (reviewed by References [3,40]). Our understanding of the CREs associated with the HoxA cluster remains less well studied, but what is known reflects a similar arrangement to that seen for the HoxD cluster $[60,61]$.

Descriptive and functional characterization of Hox expression in tetrapod limbs provides a partial mechanistic explanation for observed patterns of morphological regionality along the P-D axis. The ZPA and AER maintain a Shh-Fgf feedback loop that regulates appendage outgrowth and provides positional information required for patterning the P-D axis of the autopod and digits. $5^{\prime}$ HoxA/D genes work combinatorially and are also co-regulated by the ZPA to define the regulatory environment that gives the limb its P-D regionality. However, because tetrapod limbs are so anatomically distinctive-possessing an autopod, but lacking the pro- and mesopterygium and distal fin rays of finned vertebratesthe study of limb development alone cannot fully uncover the developmental basis of appendage diversity or its origins.

\section{Comparative Developmental Studies Reveal Deep Homologies}

\subsection{Homologies and Novelty}

While precise definitions are often debated, evolutionary novelties are structures which lack a homologous morphological precursor in an outgroup or hypothesized ancestor $[62,63]$. Although evolutionarily novel structures appear to arise de novo with no clear antecedent, nothing comes from nothing; while adult structures may have no clear homologs, they generally arise from pre-existing cell populations and may involve the redeployment of GRNs in new embryonic contexts [64]. Therefore, although a structure itself may appear novel, the genes, GRNs, and cell populations from which it is derived may not be [65]. Conversely, homologous structures need not always employ homologous developmental regulatory mechanisms [66]. Therefore, structures are referred to as novel not when they truly lack a precursor, but rather when they represent a new combination of ancestral developmental features, or when they differ so dramatically from their antecedents as to no longer be recognizable. The lack of one-to-one correlations between homology of structures and homology of the underlying GRNs has added a layer of complexity to traditional definitions of homology. Shared GRNs between non-homologous structures have been described as representing a different kind of homology: deep homology $[65,67]$.

The tetrapod limb has been described as an evolutionary novelty [67,68]. Although limbs are clearly derived from fins, and traditional wisdom states that the P-D regions of the tetrapod limb represent a subdivided ancestral metapterygium, assigning structural homologies to many fin and limb skeletal elements remains guesswork and some structures do appear to arise without clear precursors (e.g., the autopod). However, the observed patterns of anatomical variation demonstrate the existence of distinct morphological regions 
(e.g., metapterygium and fin rays) [20] which are recognizable across phylogeny. The derivatives of these regions behave semi-autonomously across the course of evolution (with contained elements being lost, gained, or transformed simultaneously). This shared behavior suggests that elements within a region are at least partially under shared genetic control. Therefore, these anatomical and evolutionary patterns pose testable hypotheses of deep homology of region derivatives across phylogeny. Testing these hypotheses requires a comparative developmental approach.

\subsection{Developmental Comparisons: Fgf and Shh}

In the teleost zebrafish (Danio rerio), Shh is expressed posteriorly in the pectoral fins in a pattern consistent with the ZPA of tetrapods [16,42]. As in tetrapods, appendage specific expression of $S h$ in zebrafish is driven by a ZRS recognizable by its highly conserved sequence and position in the genome [69]. Studies in two chondrichthyans (the little skate Raja erinacea and bamboo shark Chiloscyllium punctatum) and in paddlefish (Polyodon spathula, a non-teleost actinopterygian) also reveal conserved ZPA-like patterns of Shh expression (Figure 3C), conservation of the ZPA Regulatory Sequence (ZRS), and shared Shh function with tetrapods $[69,70]$. Experimental manipulations of $S h$ expression in zebrafish indicate that, as in tetrapods, Shh is required for normal fin outgrowth, and for anterior expression of HoxA13 and HoxD13 [71]. These studies also demonstrate a similar functional relationship between the zebrafish ZPA and a morphologically distinct AER [72,73] that expresses a suite of Fgfs, including Fgf8 [74-76]. In Shh knockout zebrafish, the AER fails to express $F g f 8$, supporting a conserved interaction between the ZPA and AER [71]. A molecularly distinct AER is also present in other non-tetrapod vertebrates, such as lungfish (Neoceratodus forsteri) [77], paddlefish, and catshark (Scyliorhinus canicula) [21] (Figure 3C). However, the AERs in tetrapods and finned vertebrates are not identical; while the tetrapod AER is a persistent structure that remains throughout limb bud outgrowth, in fins the AER is transient, and transitions into an apical fin fold (AF) early in development [78]. Although the AER and AF are structurally and histologically distinct, the AF continues to express AER Fgfs [21,73].

One obvious difference between finned vertebrates and tetrapods is the absence of dermal fin rays in limbs (Figure 2). Understanding this evolutionary loss requires an understanding of the mechanisms of fin ray development. In zebrafish, fin rays develop within the apical fin fold. Once the AF elongates, elastoidin fibrils called actinotrichia form, which straighten the AF and provide scaffolding for migrating mesenchymal cells that will form the adult fin rays [79]. Genes in the actinodin family (zebrafish And1-4) encode structural proteins required for actinotrichia formation. Zebrafish And1/And2 double morphants (morpholino-mediated gene knockdowns) display only rudimentary pectoral fin buds and fail to develop an AF [16]. Comparative genomics suggests a progressive loss of Actinodin genes in the sarcopterygian lineage, with two copies present in the most basal living sarcopterygian (coelacanth) [80], one copy in the sister group to tetrapods (lungfishes) [81], and none in any surveyed tetrapod genome [16]. The And1/2 knockdown phenotype and this pattern of gene loss suggests that the loss of And genes may play a role in the loss of fin rays in the tetrapod lineage. However, it is also possible that structural fin rays were lost first in tetrapods, and that And genes were subsequently freed from stabilizing selection allowing them to degenerate.

A second more longstanding hypothesis to explain the loss of fin rays in tetrapods was proposed by Peter Thorogood [82] and termed the "clock model". The clock model invokes heterochrony (the changing in timing of developmental events) to explain the loss of the AF and fin rays, and the expansion of the endoskeleton to the distal edge of the limb bud. This model proposes that a heterochronic delay in the AER to AF transition would lead to a smaller fin fold and an extension of the region containing endochondral derivatives, therefore resulting in reduced adult fin rays and an increased endoskeleton as seen in tetrapods. This hypothesis makes two fundamental assumptions: (1) that there are distinct proximo-distally segregated regions of the fin that are competent to produce only 
endoskeletal or dermatoskeletal elements, respectively; and (2) that the reduction in one region would lead to the concomitant expansion of the other. Zebrafish studies showing that repeated amputation of the AF led to moderate expansion of endochondrally ossifying distal radials lent the hypothesis weak support [83], but while elegant, intuitive, and widely cited, the clock model is not supported by more recent descriptive and experimental data.

The clock model makes specific predictions about possible appendage morphologies and implies that there should be a consistent molecular identity associated with endoskeleton producing versus dermatoskeleton producing regions. For example, morphologies in which the appendage possesses extensive endoskeleton and dermatoskeleton, and/or where these two skeletal regions exhibit significant P-D overlap, would not be predicted to occur. Additionally, the model predicts that genes marking the autopod in tetrapods (e.g., HoxA13) would be expressed only in the endoskeleton producing proximal region of a finned vertebrate, rather than in the dermatoskeleton producing AF. Anatomically, the clock model does fit well with most fins and limbs seen in nature. However, forms such as the Devonian sarcopterygian Sauripterus present a problem for the model. Sauripterus exhibits an elaborate distal endoskeleton sandwiched between elongate dermal rays [14] (Figure 2) - a morphology in violation of the prediction that endoskeletal and dermatoskeletal regions will be proximo-distally segregated.

In terms of predicted gene expression, function, and developmental outcomes, recent studies also do not support the clock model. Work in paddlefish and catshark reveal that both proximal endoskeletal and distal AF regions are specified early in development, recognizable by region specific markers, and that these regions then expand proximo-distally throughout subsequent stages of development [21]. These same studies further probed the components of the $S h h / F g f$ transcriptional network required for distal limb outgrowth and polarization, revealing striking similarities between the developing paddlefish fin fold and the mouse autopod (Figure $3 \mathrm{C}$ ). These data suggest that fin rays and the autopod develop within the same molecularly distinct distal region, rather than being segregated as the model predicts [21]. Together, these results support an evolutionary scenario where different skeletogenic outcomes may have been acquired (autopod) and lost (dermal rays) at different points in phylogeny within a conserved distal appendage region regulated by a conserved Shh/Fgf transcriptional network.

\subsection{Developmental Comparisons: Hox Genes}

Early studies identified that the first phase of $5^{\prime}$ HoxA/D expression seen in mice is also present in zebrafish, but failed to identify the Shh dependent second phase [84], leading to the hypothesis that the second phase of Hox expression was a tetrapod novelty potentially associated with the origin of the autopod [84,85]. However, subsequent studies were able to identify aspects of a second phase in zebrafish fins [24], indicating that while the second phase of Hox expression is essential for autopod development in tetrapods, it is not autopod specific, and both phases of Hox expression were likely present in the common ancestor of zebrafish and mouse.

Investigations in paddlefish revealed a more extensive and limb-like pattern of HoxD gene expression than initially described in zebrafish [84], supporting the hypothesis that both early phase and late-phase appendage Hox expression are more ancient than first considered [86]. Detailed study of HoxD expression in paddlefish and catshark revealed persistent expression of transcripts in the distal fin fold in a pattern consistent with HoxD expression observed during autopod development [22] (Figure 3D). Expression of $5^{\prime}$ HoxD has also been documented in the posterior portions of the distal fin fold in the Australian lungfish Neoceratodus, the only finned sarcopterygian for which such gene-expression data are available [87]. Together, these results support a biphasic pattern of HoxD expression, with an early Shh independent phase in the proximal fin and a later Shh dependent phase expressed in the middle portions of the fin and in the fin fold. They also support the conclusion that, while digits and fin rays are not structurally homologous, they may 
occupy homologous regions in the developing appendage and be patterned by shared molecular mechanisms, suggesting a deep homology.

HoxA expression in both taxa also revealed marked conservation with mouse limbs, with one notable difference. In both paddlefish and catshark, Meis2, HoxA11, and HoxA13 all exhibit the same proximo-distal orientations observed in the limb, except for a nearly complete overlap between HoxA11 and HoxA13 expression in the fin fold (Figure 3D) [21]. Similar patterns of HoxA11 and HoxA13 expression are present in zebrafish [24] and in the cichlid Astatotilapia burtoni [88], suggesting that this pattern is widespread in actinopterygian pectoral fins. Investigations in non-amniote sarcopterygians have also revealed overlapping 5' HoxA expression domains. Neoceratodus exhibits overlapping HoxA11 and HoxA13 in the fin fold $[87,89]$, but also a curious proximo-distally repeating banded pattern of HoxA11 and Meis expression which is unique among characterized taxa. In at least some amphibians (e.g., Xenopus, Notopthalmus, and Ambyostoma) HoxA11 and HoxA13 expression domains are also overlapping $[88,90,91]$. The amphibian condition demonstrates that overlapping HoxA expression is not unique to fins, spatially separated expression domains are not always required for the development of a distinct zeugopod and autopod, and that the proximal restriction of HoxA11 expression may be a derived feature of amniotes.

In amniotes HoxA13 is known to suppress the activity of HoxA11, resulting in exclusive expression domains that define the zeugopod and autopod regions [92]. Recent work has demonstrated that deletion of Hox13 paralogs in zebrafish results in increased HoxA11 expression, which is consistent with a similar negative regulation of HoxA11 by HoxA13 in teleost fins. These data suggest that, although the expression domains of HoxA genes differ between amniote and non-amniote vertebrates, the regulatory interactions between these genes may be conserved [10].

\subsection{Recent Functional Studies}

Schneider et al. [93] first demonstrated experimentally that fins possess the same CREs that drive HoxD gene expression in the distal limb. They found functional conservation between HoxD enhancers in tetrapods, zebrafish, and chondrichthyans, demonstrating that these enhancer sequences could reciprocally drive reporter expression in both mouse limbs and zebrafish fins. These results confirmed gene expression patterns that pointed to a biphasic HoxD expression pattern in teleosts [24], non-teleost actinopterygians [22,86] and chondrichthyans [21,94], thus supporting that the HoxD enhancer landscape and biphasic regulation are likely as ancient as gnathostomes. Further investigations by Gehrke et al. explored the HoxA/D "regulatory archipelagos", confirming remarkable conservation between actinopterygians and tetrapods [18]. This work identified potential $5^{\prime}$ Hox enhancers in both gar (Lepisosteus osseus, a non-teleost actinopterygian) and zebrafish, generated reporter constructs containing these putative enhancers, and injected these into mouse and zebrafish embryos. These putative late phase enhancers drove reporter expression in the distal fins of zebrafish, generally in the area where distal endoskeletal radials will develop. These enhancers varied in their ability to drive expression in the mouse autopod, both between enhancers and between gar and zebrafish. These results may reflect actual changes in function of CREs across phyletic evolution, but may also reflect drift in developmental systems between the donor and host species used in the experiment [40].

In tetrapods, HoxA13 expression is autopod specific [95]. Fate-mapping experiments in zebrafish fins demonstrate that cells marked by autopodial HoxA13 CRE activity form portions of the fin fold and the dermal fin rays, and CRISPR/Cas9 inactivation of HoxA13 results in the loss or reduction of dermal fin rays, with corresponding increases in the number of endochondral distal radials [23]. Together, these results provide the first experimental demonstrations that the autopod and the fin fold/dermal rays are patterned by shared developmental regulatory mechanisms and therefore may share deep homologies. They also suggest that a developmental novelty associated with autopod origins may be the ability of HoxA13 expressing cells in the fin fold to chondrify and produce endochondral rather than dermal bones. Furthermore, these studies reconcile previous 
AER ablation results [83] without invoking heterochronic "clock models" [82] to explain the fin-to-limb transition.

Together, these advances have provided significant insight into appendage specific Hox CRE function and evolution. Additionally, they have greatly expanded our understanding of fin and limb specification, and perhaps uncovered deep regulatory homologies. However, unlike the Actinodin and Hox expression boundaries associated with P-D patterning, clear molecular markers of the ancestral morphological regions of the A-P axis have remained largely elusive. Experiments in chondrichthyans that use retinoic acid to perturb normal Shh signaling result in "posteriorized" fin anatomies, in which the proand mesopterygium are reduced or lost and the metapterygium is increased in size [70,96]. These results support the notion that subtle changes in the regulation of conserved pathways, likely through CRE evolution, can have profound phenotypic outcomes on the contribution of regions to a final appendage phenotype. A recent experimental study in zebrafish is among the first to connect shifts in both P-D and A-P identities to Hox [10]. Hawkins et al. found that zebrafish with mutations in the waslb/vav2 pathway (previously undiscussed genes in appendage development) result in enhanced expression of HoxA11 and exhibit extended posterior radials, with branching, jointing of endochondral elements, and muscle integration patterns characteristic of limbs. As the metapterygium is the only region of the ancestral paired appendage capable of generating additional P-D segmentation, these striking results point to a latent capacity within teleosts (or at least within zebrafish) to express more posteriorized "metapterygial" phenotypes, and supports earlier hypotheses that teleosts have not completely lost the metapterygium $[3,5]$.

\section{In Search of Deeper Homologies Still (Deepest Homologies)}

Decades of research into the mechanisms underlying vertebrate appendage development and evolution have provided many surprising insights, but perhaps the most consistent theme to emerge is the level of developmental conservation underlying diverse appendage anatomies. Despite extensive efforts characterizing gene expression patterns, we have yet to discover a molecular "smoking gun" for most of the dramatic transformations in appendage evolution. In fact, quite the opposite.

Investigation of vertebrate appendages not considered structurally homologous with paired fins or limbs indicate that aspects of the core GRN deployed during early fin and limb development are not paired-appendage specific. These studies reveal that elements of the "paired-appendage" GRN, including biphasic Hox and a Shh-Fgf feedback loop, are also deployed during median (dorsal and anal) fin development in bony and cartilaginous fishes [94] and that expression of at least some genes in this network are controlled by enhancers shared by both median and paired fins [97]. Because median fins arose in the vertebrate lineage prior to paired fins, this led to the hypothesis that paired fins arose by cooption of a preexisting median fin GRN. However, substantial portions of this network also function in the development of a variety of other structures, including mammalian external genitalia [98,99], the branchial arches of chondrichthyans [100,101], and the appendages of non-vertebrate animals such as arthropods [102] and spiralians [103]. Taken together, these data suggest that the "paired appendage" GRN was present in the common ancestor of the Bilateria and has been repeatedly (and convergently) coopted during the development of diverse appendage types across the clade.

The deep homology of metazoan appendages suggests that differences in the expression of patterning genes may not underlie many dramatic differences in appendage anatomy, which sends us in search of additional mechanisms for generating divergent morphologies. Different anatomies may share conserved core GRNs and CREs, but they still differ in the cellular dynamics that govern their formation [104]. In the 1950s, mathematician A.M. Turing proposed that many biological patterns could be the result of reactiondiffusion interactions in which diffusible substances (e.g., secreted proteins) interact with each other to generate spatially periodic patterns [105]. Alterations in the interactions between these substances may produce dramatic shifts in the resulting morphological 
pattern [106], and models have been proposed for how a Turing-type mechanism might explain limb development and skeletal patterns [107]. Experimental studies in mice [108] and catshark [109] reveal the presence of a conserved Turing-type process involved in the patterning the distal portions of the autopod and distal endoskeletal radials. Further evidence suggests that Turing-type mechanisms pattern limbs through galectin family member interactions [110] and digit number and size through HoxA/D interactions [111]. These results point to an important role of cellular dynamics in the generation of divergent morphologies.

Turing mechanisms have not yet been invoked in the patterning of fin rays, but they have been implicated in the patterning of a variety of epithelial appendages, including bird feathers [112], mammalian hair [113], and chondrichthyan dermal denticles (scales) [114]. These studies suggest that reaction-diffusion modulated epithelial appendage patterning is an ancient and conserved feature of vertebrates [114]. Though fin rays and epithelial appendages appear quite different, the longstanding hypothesis for fin-ray origins is that they were originally derived from scales [115], suggesting that a similar patterning mechanism may also be associated with fin ray patterning. Further comparative studies in finned vertebrates will be required to test the antiquity of Turing mechanisms in the distal appendage and ask whether modifications of cellular dynamics may underlie changes in appendage morphology not explained by modifications of gene-expression patterns.

The term "deep homology" was originally proposed to describe in "genetic mechanisms" [67] or "genetic regulatory circuits" [65], and it is generally used to describe shared GRNs and CREs underlying the development of homologous or non-homologous structures. However, our growing understanding of additional levels of developmental dynamics at play adds another level of complexity to our definitions of homology. When shared genetic mechanisms can result in divergent anatomies when played out on a background of altered cellular dynamics, what does this mean for the homology of the resulting structures? Does this require an expansion of our definition of deep homology, or does this describe an independent phenomenon?

\section{Conclusions}

Data from extant forms and fossils demonstrate that vertebrate paired appendages are organized into distinct morphological regions, and that the loss and gain of whole regions are responsible for the range of observed appendage anatomies across vertebrates. Developmental data partially support this hypothesis, but they also provide evidence of ancient conserved patterning mechanisms underlying the origin of "new" morphological regions, and retention of cryptic regionalization in cases of structural loss. These data tell a story about the conservation of genetic regulatory mechanisms underlying dramatic morphological innovation.

The autopod is a classic example of evolutionary novelty. Descriptive and experimental data demonstrate that the fin-fold region and the autopod share a deep regulatory homology, as autopodial patterning genes are also expressed in the fin fold. This suggests that the fin-fold region was not completely lost during the tetrapod transition, and the autopod was not completely novel. Instead, the origin of the autopod can be best viewed as a transformation of skeletogenic outcomes within the distal region of the appendage, from exclusively dermatoskeletal to an intermediate state with both dermal and endochondral potential in forms such as Sauripterus, Titaalik, and Elpistostege, to exclusively endochondral in tetrapods. The lungfish Neoceratodus may represent a variant of this intermediate state, a hypothesis sure to be tested by future developmental studies in this taxon. A new mechanistic view of the origin of limbs raises new questions, such as how HoxA13-expressing cells in the fin fold became competent to chondrify, where previously they could not.

The loss of the metapterygium in teleosts has been widely accepted [11,12]. However, recent experiments have uncovered latent developmental potentials that recapitulate metapterygial-like anatomies and extended distal Hox expression zones in zebrafish [10], suggesting that this apparent loss was not complete at the molecular level and the potential 
to produce Gegenbaur's archetypical fin remains. For tetrapods, neither natural diversity nor mutant screens have revealed the re-emergence of a polybasal limb, but this remains to be considered an absence of evidence that tetrapods lack a latent capacity hidden away. A full integration of datasets may someday allow us to test hypotheses as to whether all vertebrate appendages retain the latent potential to generate the archetypical anatomy. If so, we may come to view anatomical patterns in teleosts and tetrapods as anteriorized and posteriorized variants of a common developmental template, rather than from the current perspective of anatomical loss.

Broadly comparative studies across a diversity of appendage types and animal groups also reveal that what was thought to be a paired-appendage-specific GRN has a much more ancestral provenance. These extensive similarities support the deep homology of many metazoan appendages and suggest the potential for mechanisms beyond simple changes in gene expression to produce morphological divergence. These data also suggest that further investigations into the expression patterns of canonical appendage patterning genes are unlikely to yield answers about the origins of novel appendage phenotypes at deep nodes in vertebrate phylogeny. Instead, future insights will likely come from the continued exploration of how CRE landscape evolution and biophysical interactions can generate novel phenotypes.

As we further understand the developmental mechanisms of organismal diversity, we must also readdress our concepts of homology. Recent insights have demonstrated that diverse anatomies may also be generated by altered cellular dynamics via modulation of a Turing-like mechanism [111]. In such cases, small regulatory changes may result in very different anatomical outcomes [96]. Further experiments and models may tell us whether there is promise here to truly uncover the transformational rules that connect developmental mechanisms and classic structural homologies, as well as the developmental basis of vertebrate paired appendage diversification.

Author Contributions: A.N.C. and M.C.D. conceived of and designed the review; A.N.C., A.E., M.L.F. and B.D.K. performed the literature searches and analyses; A.N.C. conceived of and designed all images; A.N.C. led the writing with contributions from A.E. and M.C.D. All authors have read and agreed to the published version of the manuscript.

Funding: This research was funded by the National Science Foundation, grant number 1853949, to M.C.D.

Conflicts of Interest: The authors declare no conflict of interest.

\section{References}

1. Owen, R. On the Nature of Limbs; John Van Voorst: London, UK, 1849; 119p. [CrossRef]

2. Balfour, F.M. On the development of the skeleton of the paired fins of Elasmobranchii, considered in relation to its bearings on the nature of the limbs of the Vertebrata. Proc. Zool. Soc. Lond. 1881, 1881, 656-671. [CrossRef]

3. Davis, M.C. The deep homology of the autopod: Insights from Hox gene regulation. Integr. Comp. Biol. 2013, 53, 224-232. [CrossRef] [PubMed]

4. Nakamura, T.; Schneider, I.; Shubin, N.H. Evolution: The deep genetic roots of tetrapod-specific traits. Curr. Biol. 2021, 31, R467-R469. [CrossRef]

5. Gegenbaur, C. Untersuchungen zur Vergleichenden Anatomie der Wirbeltiere; Wilhelm Engelmann: Lepzig, Germany, 1865; Volume II, 176p. [CrossRef]

6. Coates, M.I. The evolution of paired fins. Theory Biosci. 2003, 122, 266-287. [CrossRef]

7. Davis, M.C.; Shubin, N.H.; Force, A. Pectoral fin and girdle development in the basal actinopterygians Polyodon spathula and Acipenser transmontanus. J. Morphol. 2004, 628, 608-628. [CrossRef] [PubMed]

8. Zhu, M.; Yu, X. Stem sarcopterygians have primitive polybasal fin articulation. Biol. Lett. 2009, 5, 372-375. [CrossRef] [PubMed]

9. Gegenbaur, C. Elements of Comparative Anatomy, 2nd ed.; Macmillan and Co.: London, UK, 1878; 645p.

10. Hawkins, M.B.; Henke, K.; Harris, M.P. Latent developmental potential to form limb-like skeletal structures in zebrafish. Cell 2021, 184, 899-911. [CrossRef] [PubMed]

11. Grandel, H. Approaches to a comparison of fin and limb structure and development. Theory Biosci. 2003, 122, 288-301. [CrossRef]

12. Goodrich, E.S. Studies on the Structure \& Development of Vertebrates; Macmillan and Co. Ltd.: London, UK, 1930; 837p.

13. Janvier, P. Early Vertebrates; Oxford University Press: Oxford, UK, 1996; 408p. 
14. Davis, M.C.; Shubin, N.H.; Daeschler, E.B. A new specimen of Sauripterus taylori (Sarcopterygii; Osteichthyes) from the Famennian Catskill Formation of North America. J. Vertebr. Paleontol. 2004, 24, 26-40. [CrossRef]

15. Shubin, N.H.; Daeschler, E.B.; Jenkins, F.A. The pectoral fin of Tiktaalik roseae and the origin of the tetrapod limb. Nature 2006, 440, 764-771. [CrossRef]

16. Zhang, J.; Wagh, P.; Guay, D.; Sanchez-Pulido, L.; Padhi, B.K.; Korzh, V.; Andrade-Navarro, M.A.; Akimenko, M.A. Loss of fish actinotrichia proteins and the fin-to-limb transition. Nature 2010, 466, 234-237. [CrossRef]

17. Daeschler, E.B.; Shubin, N. Fish with fingers? Nature 1998, 391, 133. [CrossRef]

18. Gehrke, A.R.; Schneider, I.; de la Calle-Mustienes, E.; Tena, J.J.; Gomez-Marin, C.; Chandran, M.; Nakamura, T.; Braasch, I.; Postlethwait, J.H.; Gómez-Skarmeta, J.L.; et al. Deep conservation of wrist and digit enhancers in fish. Proc. Natl. Acad. Sci. USA 2015, 112, 803-808. [CrossRef]

19. Woltering, J.M.; Noordermeer, D.; Leleu, M.; Duboule, D. Conservation and divergence of regulatory strategies at Hox loci and the origin of tetrapod digits. PLoS Biol. 2014, 12, e1001773. [CrossRef]

20. Shubin, N.H.; Davis, M.C. Modularity in the evolution of vertebrate appendages. In Modularity in Development and Evolution; Schlosser, G., Wagner, G., Eds.; University of Chicago Press: Chicago, IL, USA, 2004; pp. 429-440.

21. Tulenko, F.J.; Massey, J.L.; Holmquist, E.; Kigundu, G.; Thomas, S.; Smith, S.M.E.; Mazan, S.; Davis, M.C. Fin-fold development in paddlefish and catshark and implications for the evolution of the autopod. Proc. R. Soc. B Biol. Sci. 2017, 284. [CrossRef]

22. Tulenko, F.J.; Augustus, G.J.; Massey, J.L.; Sims, S.E.; Mazan, S.; Davis, M.C. HoxD expression in the fin-fold compartment of basal gnathostomes and implications for paired appendage evolution. Sci. Rep. 2016, 6, 1-10. [CrossRef]

23. Nakamura, T.; Gehrke, A.R.; Lemberg, J.; Szymaszek, J.; Shubin, N.H. Digits and fin rays share common developmental histories. Nature 2016, 537, 225-228. [CrossRef]

24. Ahn, D.; Ho, R.K. Tri-phasic expression of posterior Hox genes during development of pectoral fins in zebrafish: Implications for the evolution of vertebrate paired appendages. Dev. Biol. 2008, 322, 220-233. [CrossRef]

25. Schneider, I.; Shubin, N.H. The origin of the tetrapod limb: From expeditions to enhancers. Trends Genet. 2013, $29,419-426$. [CrossRef]

26. Cloutier, R.; Clement, A.M.; Lee, M.S.Y.; Noël, R.; Béchard, I.; Roy, V.; Long, J.A. Elpistostege and the origin of the vertebrate hand. Nature 2020, 579, 549-554. [CrossRef]

27. Wagner, G.P.; Chiu, C.H. The Tetrapod Limb: A Hypothesis on Its Origin. J. Exp. Zool. 2001, 291, 226-240. [CrossRef]

28. Woltering, J.M.; Duboule, D. The origin of digits: Expression patterns versus regulatory mechanisms. Dev. Cell 2010, 18, 526-532. [CrossRef]

29. Coates, M.I. The Devonian tetrapod Acanthostega gunnari Jarvik: Postcranialanatomy, basal tetrapod interrelationships and patterns of skeletal evolution. Trans. R. Soc. Edinb. 1996, 87, 363-421. [CrossRef]

30. Tabin, C.; Wolpert, L. Rethinking the proximodistal axis of the vertebrate limb in the molecular era. Genes Dev. 2007, 21, 1433-1442. [CrossRef]

31. Delgado, I.; Torres, M. Coordination of limb development by crosstalk among axial patterning pathways. Dev. Biol. 2017, 429, 382-386. [CrossRef]

32. Cohn, M.J.; Patel, K.; Krumlauf, R.; Wilkinson, D.G.; Clarke, J.D.W.; Tickle, C. Hox9 genes and vertebrate limb specification. Nature 1997, 387, 97-100. [CrossRef] [PubMed]

33. Tanaka, M.; Tickle, C. Tbx18 and boundary formation in chick somite and wing development. Dev. Biol. 2004, 268, 470-480. [CrossRef]

34. Fernandez-Teran, M.; Ros, M.A. The Apical Ectodermal Ridge: Morphological aspects and signaling pathways. Int. J. Dev. Biol. 2008, 52, 857-871. [CrossRef]

35. Martin, G.R. The roles of FGFs in the early development of vertebrate limbs. Genes Dev. 1998, 12, 1571-1586. [CrossRef]

36. Lewandoski, M.; Sun, X.; Martin, G.R. Fgf8 signalling from the AER is essential for normal limb development. Nat. Genet. 2000, 26, 460-463. [CrossRef]

37. Sun, X.; Mariani, F.V.; Martin, G.R. Functions of FGF signalling from the apical ectodermal ridge in limb development. Nature 2002, 418, 501-508. [CrossRef]

38. Beermann, F.; Kaloulis, K.; Hofmann, D.; Murisier, F.; Bucher, P.; Trumpp, A. Identification of evolutionary conserved regulatory elements in the mouse Fgf8 locus. Genesis 2006, 44, 1-6. [CrossRef]

39. Marinić, M.; Aktas, T.; Ruf, S.; Spitz, F. An integrated holo-enhancer unit defines tissue and gene specificity of the fgf8 regulatory landscape. Dev. Cell 2013, 24, 530-542. [CrossRef]

40. Gehrke, A.R.; Shubin, N.H. Cis-regulatory programs in the development and evolution of vertebrate paired appendages. Semin. Cell Dev. Biol. 2016, 57, 31-39. [CrossRef] [PubMed]

41. Riddle, R.D.; Johnson, R.L.; Laufer, E.; Tabin, C. Sonic hedgehog mediates the polarizing activity of the ZPA. Cell 1993, 75, 1401-1416. [CrossRef]

42. Krauss, S.; Concordet, J.P.; Ingham, P.W. A functionally conserved homolog of the Drosophila segment polarity gene hh is expressed in tissues with polarizing activity in zebrafish embryos. Cell 1993, 75, 1431-1444. [CrossRef]

43. Tickle, C.; Towers, M. Sonic hedgehog signaling in limb development. Front. Cell Dev. Biol. 2017, 5, 1-19. [CrossRef] [PubMed]

44. Sagai, T.; Hosoya, M.; Mizushina, Y.; Tamura, M.; Shiroishi, T. Elimination of a long-range cis-regulatory module causes complete loss of limb-specific Shh expression and truncation of the mouse limb. Development 2005, 132, 797-803. [CrossRef] 
45. Zeller, R.; López-Ríos, J.; Zuniga, A. Vertebrate limb bud development: Moving towards integrative analysis of organogenesis. Nat. Rev. Genet. 2009, 10, 845-858. [CrossRef]

46. Niswander, L.; Jeffrey, S.; Martin, G.R.; Tickle, C. A positive feedback loop coordinates growth and patterning in the vertebrate limb. Nature 1994, 371, 609-612. [CrossRef]

47. Tanaka, M.; Tamura, K.; Noji, S.; Nohno, T.; Ide, H. Induction of additional limb at the dorsal-ventral boundary of a chick embryo. Dev. Biol. 1997, 182, 191-203. [CrossRef] [PubMed]

48. Tickle, C. The contribution of chicken embryology to the understanding of vertebrate limb development. Mech. Dev. 2004, 121, 1019-1029. [CrossRef] [PubMed]

49. Zakany, J.; Duboule, D. The role of Hox genes during vertebrate limb development. Curr. Opin. Genet. Dev. 2007, 17, 359-366. [CrossRef]

50. Davis, A.P.; Witte, D.P.; Hsieh-Li, H.M.; Potter, S.S.; Capecchi, M.R. Absence of radius and ulna in mice lacking hoxa-11 and hoxd-11. Nature 1995, 375, 791-795. [CrossRef]

51. Fromental-Ramain, C.; Warot, X.; Messadecq, N.; LeMeur, M.; Dollé, P.; Chambon, P. Hoxa-13 and Hoxd-13 play a crucial role in the patterning of the limb autopod. Development 1996, 122, 2997-3011. [CrossRef]

52. Mercader, N.; Leonardo, E.; Azplazu, N.; Serrano, A.; Morata, G.; Martínez, C.A.; Torres, M. Conserved regulation of proximodistal limb axis development by Meis1/Hth. Nature 1999, 402, 425-429. [CrossRef]

53. Mercader, N.; Leonardo, E.; Piedra, M.E.; Martinez-A, C.; Ros, M.A.; Torres, M. Opposing RA and FGF signals control proximodistal vertebrate limb development through regulation of Meis genes. Development 2000, 127, 3961-3970. [CrossRef]

54. Delgado, I.; López-Delgado, A.C.; Alberto, R.D.; Giovinazzo, G.; Cadenas, V.; Fernández-De-Manuel, L.; Sánchez-Cabo, F.; Anderson, M.J.; Lewandoski, M.; Torres, M. Proximo-distal positional information encoded by an Fgf-regulated gradient of homeodomain transcription factors in the vertebrate limb. Sci. Adv. 2020, 6, 1-10. [CrossRef]

55. Tarchini, B.; Duboule, D. Control of Hoxd genes' collinearity during early limb development. Dev. Cell 2006, 10, 93-103. [CrossRef]

56. Lonfat, N.; Duboule, D. Structure, function and evolution of topologically associating domains (TADs) at HOX loci. FEBS Lett. 2015, 589, 2869-2876. [CrossRef]

57. Andrey, G.; Montavon, T.; Mascrez, B.; Gonzalez, F.; Noordermeer, D.; Leleu, M.; Trono, D.; Spitz, F.; Duboule, D. A switch between topological domains underlies HoxD genes collinearity in mouse limbs. Science 2013, 340, 1234167. [CrossRef]

58. Montavon, T.; Soshnikova, N.; Mascrez, B.; Joye, E.; Thevenet, L.; Splinter, E.; De Laat, W.; Spitz, F.; Duboule, D. A regulatory archipelago controls hox genes transcription in digits. Cell 2011, 147, 1132-1145. [CrossRef] [PubMed]

59. Spitz, F.; Gonzalez, F.; Duboule, D. A global control region defines a chromosomal regulatory landscape containing the HoxD cluster. Cell 2003, 113, 405-417. [CrossRef]

60. Lehoczky, J.A.; Innis, J.W. BAC transgenic analysis reveals enhancers sufficient for Hoxa13 and neighborhood gene expression in mouse embryonic distal limbs and genital bud. Evol. Dev. 2008, 10, 421-432. [CrossRef]

61. Berlivet, S.; Paquette, D.; Dumouchel, A.; Langlais, D.; Dostie, J.; Kmita, M. Clustering of tissue-specific sub-TADs accompanies the regulation of HoxA genes in developing limbs. PLoS Genet. 2013, 9, e1004018. [CrossRef]

62. Müller, G.B.; Wagner, G.P. Novelty in evolution: Restructuring the concept. Annu. Rev. Ecol. Syst. 1991, 22, 229-256. [CrossRef]

63. Hall, B.K. Consideration of the neural crest and its skeletal derivatives in the context of novelty/innovations. J. Exp. Zool. Part B Mol. Dev. Evol. 2005, 304, 548-557. [CrossRef]

64. True, J.R.; Carroll, S.B. Gene co-option in physiological and morphological evolution. Annu. Rev. Cell Dev. Biol. 2002, 18, 53-80. [CrossRef]

65. Shubin, N.; Tabin, C.; Carroll, S. Deep homology and the origins of evolutionary novelty. Nature 2009, 457, 818-823. [CrossRef]

66. Wray, G.A.; Abouheif, E. When is homology not homology? Curr. Opin. Genet. Dev. 1998, 8, 675-680. [CrossRef]

67. Shubin, N.; Tabin, C.; Carroll, S. Fossils, genes and the evolution of animal limbs. Nature 1997, 388, 639-648. [CrossRef]

68. Shubin, N.H. Origin of evolutionary novelty: Examples from limbs. J. Morphol. 2002, 252, 15-28. [CrossRef]

69. Lettice, L.A.; Heaney, S.J.H.; Purdie, L.A.; Li, L.; de Beer, P.; Oostra, B.A.; Goode, D.; Elgar, G.; Hill, R.E.; de Graaff, E. A long-range Shh enhancer regulates expression in the developing limb and fin and is associated with preaxial polydactyly. Hum. Mol. Genet. 2003, 12, 1725-1735. [CrossRef]

70. Dahn, R.D.; Davis, M.C.; Pappano, W.N.; Shubin, N.H. Sonic hedgehog function in chondrichthyan fins and the evolution of appendage patterning. Nature 2007, 445, 311-314. [CrossRef]

71. Neumann, C.J.; Grandel, H.; Gaffield, W.; Schulte-Merker, S.; Nüsslein-Volhard, C. Transient establishment of anteroposterior polarity in the zebrafish pectoral fin bud in the absence of sonic hedgehog activity. Development 1999, 126, 4817-4826. [CrossRef]

72. Grandel, H.; Schulte-Merker, S. The development of the paired fins in the zebrafish (Danio rerio). Mech. Dev. 1998, 79, 99-120. [CrossRef]

73. Mercader, N. Early steps of paired fin development in zebrafish compared with tetrapod limb development. Dev. Growth Differ. 2007, 49, 421-437. [CrossRef]

74. Reifers, F.; Böhli, H.; Walsh, E.C.; Crossley, P.H.; Stainier, D.Y.R.; Brand, M. Fgf8 is mutated in zebrafish acerebellar (ace) mutants and is required for maintenance of midbrain-hindbrain boundary development and somitogenesis. Development 1998, 125, 2381-2395. [CrossRef]

75. Grandel, H.; Draper, B.W.; Schulte-Merker, S. Dackel acts in the ectoderm of the zebrafish pectoral fin bud to maintain AER signaling. Development 2000, 127, 4169-4178. [CrossRef] 
76. Jovelin, R.; He, X.; Amores, A.; Yan, Y.L.; Shi, R.; Qin, B.; Roe, B.; Cresko, W.A.; Postlethwait, J.H. Duplication and divergence of fgf8 functions in teleost development and evolution. J. Exp. Zool. Part B Mol. Dev. Evol. 2007, 308, 730-743. [CrossRef]

77. Hodgkinson, V.S.; Ericsson, R.; Johanson, Z.; Joss, J.M.P. The apical ectodermal ridge in the pectoral fin of the Australian lungfish (Neoceratodus forsteri): Keeping the fin to limb transition in the fold. Acta Zool. 2009, 90, 253-263. [CrossRef]

78. Wood, A. Early pectoral fin development and morphogenesis of the apical ectodermal ridge in the killifish, Aphysosemion scheeli. Anat. Rec. 1982, 204, 349-356. [CrossRef]

79. Géraudie, J. No Initiation of the actinotrichial development in the early fin bud of the fish, Salmo. J. Morphol. 1977, 151, 353-361. [CrossRef]

80. Nikaido, M.; Noguchi, H.; Nishihara, H.; Toyoda, A.; Suzuki, Y.; Kajitani, R.; Suzuki, H.; Okuno, M.; Aibara, M.; Ngatunga, B.P.; et al. Coelacanth genomes reveal signatures for evolutionary transition from water to land. Genome Res. 2013, 23, 1740-1748. [CrossRef]

81. Wang, K.; Wang, J.; Zhu, C.; Yang, L.; Ren, Y.; Ruan, J.; Fan, G.; Hu, J.; Xu, W.; Bi, X.; et al. African lungfish genome sheds light on the vertebrate water-to-land transition. Cell 2021, 184, 1362-1376.e18. [CrossRef]

82. Thorogood, P. The development of the teleost fin and implications for our understanding of tetrapod limb evolution. Dev. Patterning Vert. Limb 1991, 205, 347-354. [CrossRef]

83. Yano, T.; Abe, G.; Yokoyama, H.; Kawakami, K.; Tamura, K.; Yano, T.; Abe, G.; Yokoyama, H.; Kawakami, K.; Tamura, K. Mechanism of pectoral fin outgrowth in zebrafish development. Development 2012, 139, 4291. [CrossRef]

84. Sordino, P.; van der Hoeven, F.; Duboule, D. Hox gene expression in teleost fins and the origin of vertebrate digits. Nature 1995 375, 678-681. [CrossRef]

85. Sordino, P.; Duboule, D. A molecular approach to the evolution of vertebrate paired appendages. Trends Ecol. Evol. 1996, 11, 114-119. [CrossRef]

86. Davis, M.C.; Dahn, R.D.; Shubin, N.H. An autopodial-like pattern of Hox expression in the fins of a basal actinopterygian fish Nature 2007, 447, 473-477. [CrossRef]

87. Woltering, J.M.; Irisarri, I.; Ericsson, R.; Joss, J.M.P.; Sordino, P.; Meyer, A. Sarcopterygian fin ontogeny elucidates the origin of hands with digits. Sci. Adv. 2020, 6, 1-8. [CrossRef]

88. Woltering, J.M.; Holzem, M.; Meyer, A. Lissamphibian limbs and the origins of tetrapod hox domains. Dev. Biol. 2019, 456, 138-144. [CrossRef]

89. Langellotto, F.; Fiorentino, M.; Felice, E.; Caputi, L.; Nittoli, V.; Joss, J.M.P.; Sordino, P. Expression of meis and hoxa11 in dipnoan and teleost fins provides new insights into the evolution of vertebrate appendages. Evodevo 2018, 9, 1-11. [CrossRef]

90. Wagner, G.P.; Khan, P.A.; Blanco, M.J.; Misof, B.; Liversage, R.A. Evolution of hoxa-11 expression in amphibians: Is the urodele autopodium an innovation? Am. Zool. 1999, 39, 686-694. [CrossRef]

91. Bickelmann, C.; Frota-Lima, G.N.; Triepel, S.K.; Kawaguchi, A.; Schneider, I.; Fröbisch, N.B. Noncanonical Hox, Etv4, and Gli3 gene activities give insight into unique limb patterning in salamanders. J. Exp. Zool. Part B Mol. Dev. Evol. 2018, 330, 138-147. [CrossRef] [PubMed]

92. Kherdjemil, Y.; Lalonde, R.L.; Sheth, R.; Dumouchel, A.; De Martino, G.; Pineault, K.M.; Wellik, D.M.; Stadler, H.S.; Akimenko, M.A.; Kmita, M. Evolution of Hoxa11 regulation in vertebrates is linked to the pentadactyl state. Nature 2016, 539, 89-92. [CrossRef] [PubMed]

93. Schneider, I.; Aneas, I.; Gehrke, A.R.; Dahn, R.D.; Nobrega, M.A.; Shubin, N.H. Appendage expression driven by the Hoxd Global Control Region is an ancient gnathostome feature. Proc. Natl. Acad. Sci. USA 2011, 108, 12782-12786. [CrossRef] [PubMed]

94. Freitas, R.; Zhang, G.; Cohn, M.J. Biphasic Hoxd gene expression in shark paired fins reveals an ancient origin of the distal limb domain. PLoS ONE 2007, 2, e754. [CrossRef]

95. Scotti, M.; Kherdjemil, Y.; Roux, M.; Kmita, M. A Hoxa13:Cre mouse strain for conditional gene manipulation in developing limb, hindgut, and urogenital system. Genesis 2015, 53, 366-376. [CrossRef]

96. Onimaru, K.; Kuraku, S.; Takagi, W.; Hyodo, S.; Sharpe, J.; Tanaka, M. A shift in anterior-posterior positional information underlies the fin-to-limb evolution. Elife 2015, 4, 1-15. [CrossRef]

97. Letelier, J.; De La Calle-Mustienes, E.; Pieretti, J.; Naranjo, S.; Maeso, I.; Nakamura, T.; Pascual-Anaya, J.; Shubin, N.H.; Schneider, I.; Martinez-Morales, J.R.; et al. A conserved Shh cis-regulatory module highlights a common developmental origin of unpaired and paired fins. Nat. Genet. 2018, 50, 504-509. [CrossRef]

98. Kondo, T.; Zákány, J.; Innis, J.W.; Duboule, D. Of fingers, toes and penises. Nature 1997, 390, 29. [CrossRef]

99. Cohn, M.J. Development of the external genitalia: Conserved and divergent mechanisms of appendage patterning. Dev. Dyn. 2011, 240, 1108-1115. [CrossRef]

100. Gillis, J.A.; Dahn, R.D.; Shubin, N.H. Shared developmental mechanisms pattern the vertebrate gill arch and paired fin skeletons. Proc. Natl. Acad. Sci. USA 2009, 106, 5720-5724. [CrossRef]

101. Gillis, J.A.; Hall, B.K. A shared role for sonic hedgehog signalling in patterning chondrichthyan gill arch appendages and tetrapod limbs. Development 2016, 143, 1313-1317. [CrossRef]

102. Pueyo, J.I.; Couso, J.P. Parallels between the proximal-distal development of vertebrate and arthropod appendages: Homology without an ancestor? Curr. Opin. Genet. Dev. 2005, 15, 439-446. [CrossRef]

103. Tarazona, O.A.; Lopez, D.H.; Slota, L.A.; Cohn, M.J. Evolution of limb development in cephalopod mollusks. Elife 2019, 8, 1-19. [CrossRef] [PubMed] 
104. Stewart, T.A.; Bhat, R.; Newman, S.A. The evolutionary origin of digit patterning. Evodevo 2017, 8, 1-7. [CrossRef]

105. Turing, A.M. The chemical basis of morphogenesis. Philos. Trans. R. Soc. Lond. B. Biol. Sci. 1952, 237, 37-72. [CrossRef]

106. Kondo, S.; Miura, T. Reaction-diffusion model as a framework for understanding biological pattern formation. Science 2010, 329, 1616-1620. [CrossRef]

107. Newman, S.A. Lineage and pattern in the developing vertebrate limb. Trends Genet. 1988, 4, 329-332. [CrossRef]

108. Raspopovic, J.; Marcon, L.; Russo, L.; Sharpe, J. Digit patterning is controlled by a Bmp-Sox9-Wnt Turing network modulated by morphogen gradients. Science 2014, 345, 566-569. [CrossRef]

109. Onimaru, K.; Marcon, L.; Musy, M.; Tanaka, M.; Sharpe, J. The fin-to-limb transition as the re-organization of a Turing pattern. Nat. Commun. 2016, 7, 11582. [CrossRef]

110. Bhat, R.; Lerea, K.M.; Peng, H.; Kaltner, H.; Gabius, H.-J.; Newman, S.A. A regulatory network of two galectins mediates the earliest steps of avian limb skeletal morphogenesis. BMC Dev. Biol. 2011, 11, 6. [CrossRef]

111. Sheth, R.; Marcon, L.; Bastida, M.F.; Junco, M.; Quintana, L.; Dahn, R.; Kmita, M.; Sharpe, J.; Ros, M.A. Hox genes regulate digit patterning by controlling the wavelength of a turing-type mechanism. Science 2012, 338, 1476-1480. [CrossRef]

112. Harris, M.P.; Williamson, S.; Fallon, J.F.; Meinhardt, H.; Prum, R.O. Molecular evidence for an activator-inhibitor mechanism in development of embryonic feather branching. Proc. Natl. Acad. Sci. USA 2005, 102, 11734-11739. [CrossRef]

113. Sick, S.; Reinker, S.; Timmer, J.; Schlake, T. WNT and DKK determine hair follicle spacing through a reaction-diffusion mechanism. Science 2006, 314, 1447-1450. [CrossRef]

114. Cooper, R.L.; Thiery, A.P.; Fletcher, A.G.; Delbarre, D.J.; Rasch, L.J.; Fraser, G.J. An ancient Turing-like patterning mechanism regulates skin denticle development in sharks. Sci. Adv. 2018, 4, 1-11. [CrossRef]

115. Goodrich, E.S. On the dermal fin-rays of fishes-living and extinct. Q. J. Microsc. Soc. 1904, 47, 465-522. [CrossRef] 